\title{
Early Fault Detection by Vibration Measurement
}

\author{
D. H. Omar, M. H. Belal, F. R. Gomaa
}

\begin{abstract}
Early fault detection by using vibration monitoring devices could help industries to avoid sudden stoppage of the machine, thus reduces machine downtime and maintenance cost to save time and money. Early fault detection by using vibration measurement devices are very useful for determining the condition of rotating elements and its analysis. In this paper, experimental studies were performed to predict misalignment faults in rotating machine which is connected with simple rigid coupling. The vibration is collected by using Microlog data collector. From results, we can easily predict misalignment in rotating machine using spectrum analysis technique.
\end{abstract}

Keywords: Diagnosis, Misalignment, Fault detection techniques, Vibration measurement.

\section{INTRODUCTION}

Condition monitoring is the best techniques, condition-based maintenance is considered the most important maintenance strategy which is used for rotating machinery. Vibration measurement is one of the most useful techniques to predict machine health and monitoring the machine faults [1]. There are several techniques for fault detection: Visual monitoring[2], Ultrasound monitoring[3],Shock pulse monitoring[4],Temperature monitoring[5], Oil condition monitoring[6], and vibration monitoring[5].

The early fault detection could help to improve machines performance and productivity during operation, to ensure operation continuity without sudden shutdown. Vibration monitoringis one of the most important technique, for detecting faults in rotating machinery [7]. Vibration monitoring advantages are summarized in fault detection and diagnosis, during normal operation and it ${ }^{<} \mathrm{s}$ recognized as non- destructive technique as well, vibration signature contains most information, it can be used for online condition monitoring and applied toinaccessible components [8]. The vibration monitoring is useful for diagnosis the common mechanical faults. The common types of mechanical faults are:

Mass unbalance, gear fault, bearing failure, misalignment, and mechanical looseness.

Manuscript received on June 13, 2021.

Revised Manuscript received on June 19, 2021.

Manuscript publishedon June 30, 2021.

* Correspondence Author

D. H. Omar*, Graduate Student, Dept. of Production Engineering and Mechanical Design, Faculty of Engineering, Menoufia University, Shebin El-Kom, Egypt. Email: doaaomar1219@gmail.com.

Dr.M. H. Belal, Dept. Production Engineering and Mechanical Design, Faculty of Engineering, Menoufia University, Shebin El-Kom, Egypt. Email: Heshambelal@gmail.com.

F. R. Gomaa, Professor, Dr., Dept. of Production Engineering and Mechanical Dwsign, Faculty of Engineering, Menoufia University, Shebin El-Kom, Egypt. Email: Fawkiagomaa@yahoo.com

(c) The Authors. Published by Blue Eyes Intelligence Engineering and Sciences Publication (BEIESP). This is an open access article under the CC BY-NC-ND license (http://creativecommons.org/licenses/by-nc-nd/4.0/)
Mass unbalance: Unbalance is defined as the center of mass does not correspond to center of rotation [9]. Unbalance reasons are an eccentricity exists due to a gab of fitting in the inner ring of a bearing, the shape of the rotor is unsymmetrical, unsymmetrical mass distribution due to machining or casting error or a deformation due to a distortion [10].

Gear fault: The gear tooth damage of the two meshing wheels cause vibration due to impact. The fault in gear is classified into two main categories: disturbed fault, and local fault [11].

Bearing defects: Bearing defects reasons are overloading, uneven wear, improper lubrication, improper manufacturing or mounting or improper design of the bearing, misalignment of bearing races. Bearing defects is classified into two main categories: distributed defects and localized defects [12].

Mechanical looseness: Vibrations caused by mechanical looseness could take place in both rotating and non- rotating machinery [13]. Mechanical looseness types: internal assembly looseness, looseness at machine to base plate interface, and structure looseness [14].

Misalignment: Misalignment is defined as the relative shaft position collinear axis deviation caused in rotating machinery during operation within normal operating conditions.Misalignment in rotating machinery is one of the most common faults causing machine failure, it causes over $70 \%$ of rotating machinery vibration problems [15]. Motor shaft misalignment decreases the motor efficiency and causes coupling failure of excessive seal lubricant leakage, increased vibration and noise, and failure of foundation bolts. Common causes of misalignment are: Improper machine assembly, Thermal distortion, Asymmetry in the applied load [16].

Misalignment could be grouped in two categories, parallel and angular. Parallel misalignment refers to the offset distance between two shafts centerlines.Parallelmisalignment can be horizontal or vertical misalignment or both. Horizontal parallel misalignment is in horizontal plane in which motor shaft centerline is shifted horizontally.

And vertical parallel misalignment is in vertical plane in which motor shaft centerline is shifted vertically. Similarly for angular misalignment it can be classified into vertical or horizontal plane. Angular misalignment in vertical plane is calculated by the angle of two collinear shafts centerline in the vertical plane. Horizontal angular misalignment is the angle between twocollinear shafts centerline in the horizontal plane [17].

Misalignment measurement methods

- $\quad$ Straight edge

- Dial indicator

- $\quad$ Laser system

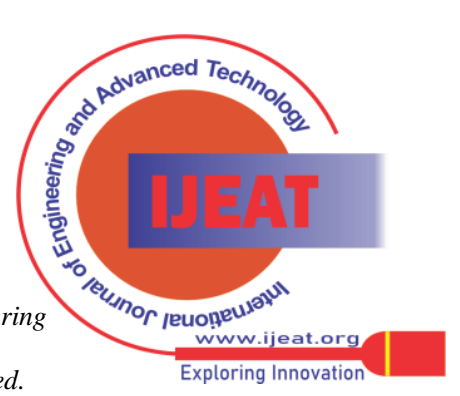


Laser systems are quicker, easier, have better accuracy, and don't require special skills to get accurate results every time [18].

Rotating machinery has lots of misalignment applications in which machinery health monitoring considering it a major malfunction to be considered. Misalignment usually effects on coupling, bearings and supports. In order to predict misalignment in such a system, an experimental study is performed on rotor shaft system with parallel misalignment and using Fast Fourier Transform (FFT) analyzer. Another paper presented a compared vibration signature for aligned and misaligned conditions for motor radial and bearing block radial direction respectively [19].

A mechanism of power transmission between motor and load is presented in another paper using different types of couplings which are common in use for industries. Another paper showed that the sensitivity of fault indicators strongly depends on the coupling features [20].Another paper studied the effects of coupling stiffness on misalignment output response of shaft connected to AC motor. In the mentioned paper the resulted response using Fast Fourier Transform FFT is analyzed and compared with Finite Element Analysis FEA using the software.

Another study is presented using Bartlett Power Spectral Density (BPSD) for fault identification in motor system such as misalignment and looseness. This approach reveals the (BPSD) provides useful information to analyze the angular misalignment and looseness faults. Moreover, axial vibration signature is always dominated due to angular misalignment. In the caseof pedestal looseness, multiple sub-harmonics peaks were appeared. From the foregoing analysis, it is proved beyond doubt that the BPSD based condition monitoring method could certainly diagnose the rotor faults if angular misalignment and looseness exist within the rotor bearing system [21].

\section{EXPERIMENTAL WORK}

The model consists of A dc motor (2850 RPM, 0.5HP), rigid coupling, bearing 1 (SY $17 \mathrm{TF}$ ), shaft, disc, bearing 2 (SY 17 TF) as shown in Fig. 1.

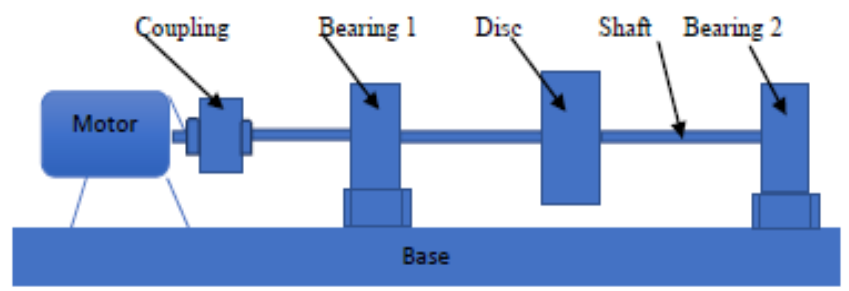

Fig.1.Schematic Diagram

The actual experimental setup (model)is driven by $0.5 \mathrm{HP}$ motor running at a speed of 2850 RPM, A rigid coupling connects the driver and driven shaft. The actual experimentalSetup consist of a shaft of $17 \mathrm{~mm}$ diameter and $500 \mathrm{~mm}$ length mounted in between the two bearing (SY 17 $\mathrm{TF}$ ). A disc of $128 \mathrm{~mm}$ diameter is fixed at the mid span of the shaft as shown in Fig. 2.

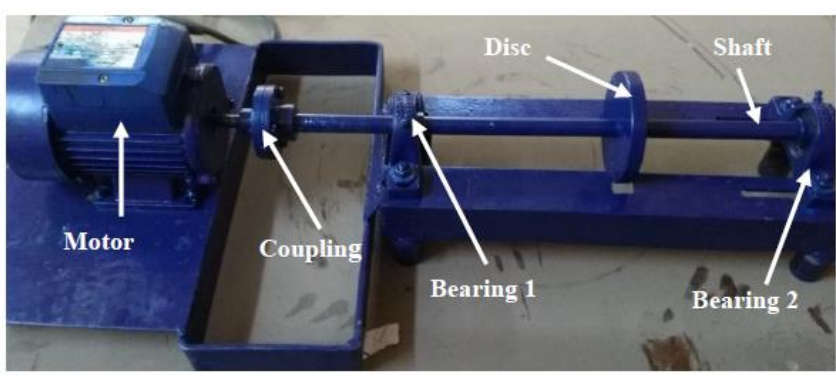

Fig. 2.Actual Experimental Setup (Model)

There are two types of measurements made in the lab:-

1. Vibration measurement.

2. Misalignment measurement.

A. Experimental Setup :

The measuring instruments used in the experimental setup:-

1. An accelerometer the output of the accelerometer is connected to the Microlog device to measurement the vibration.

2. Using device the TKSA 60 to measurement misalignment

\section{1-Vibration measurement}

B. Experiment Procedure

- Preparing for setup the device Microlog Analyzer for measurement and analysis of vibration for actual model.

- The motor speed is introduced to the measuring device and this speed is equal to 2850RPM.

- Numbering the measurement points on the model.

- Fixing the accelerometer at the places different on the measurement points.

- $\quad$ The curves (frequency domain and time domain) resulting are analyzed from the measurement process for different points and determine type of defect from this curves.

- For example, the measurement is done near the motor in the axial direction as in Fig.3.

- Also the measurement is on bearing in vertical direction as in Fig.4.

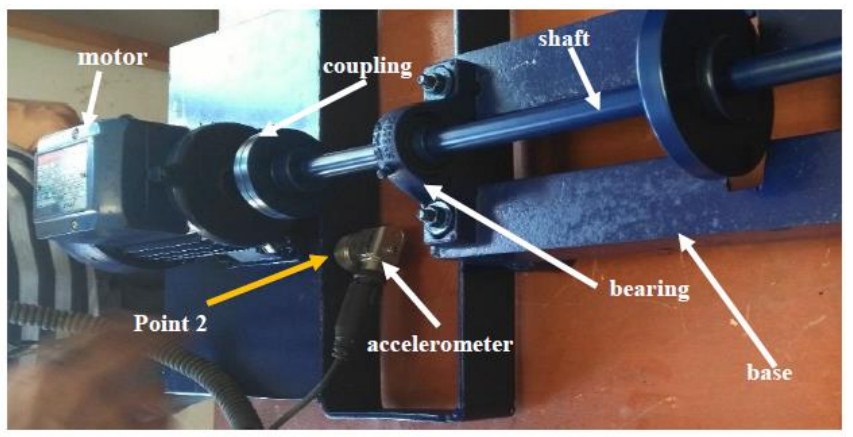

Fig. 3.Accelerometer fixing near the motor in axial direction.

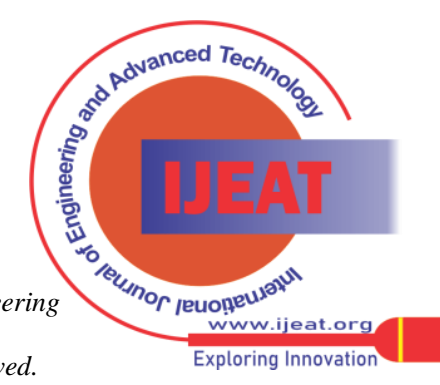




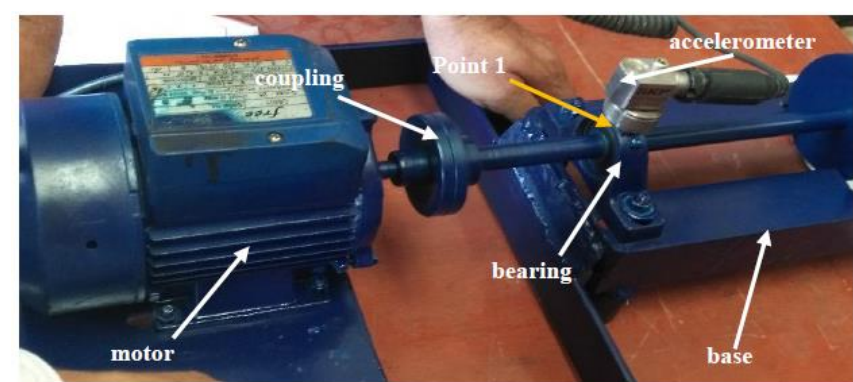

Fig.4. Accelerometer on bearing in vertical direction.

\section{RESULT AND DISCUSSION}

Sample of spectrum in Frequency domain and Time domain of axial, horizontal, and vertical direction at point (2) at motor as in Fig.6 and Fig.7.In Fig.6 Spectrum in frequency domainshows the relation between frequency (CPM) and amplitude $\mathrm{mm} / \mathrm{s}$.

1. InFig. (6-a) measurement in axial direction we notice the frequency at $1 \mathrm{x}$ equal $2906(\mathrm{CPM})=$ [48.4 $\left.\mathrm{H}_{2 .}\right]$ the peak amplitude value is $14 \mathrm{~mm} / \mathrm{s}$, it's noticed that at $2 \mathrm{x}$ the frequency equal 5734 $(\mathrm{CPM})=\left[95.5 \mathrm{H}_{\mathrm{Z}}\right]$ the amplitude value is $2.75 \mathrm{~mm} / \mathrm{s}$ and we notice also the frequency at $3 x$ equal $8606(\mathrm{CPM})=\left[143.4 \mathrm{H}_{\mathrm{Z}}\right]$ the amplitude value is $4.5 \mathrm{~mm} / \mathrm{s}$.Table Ishown as value of amplitude and frequency.

2. In Fig. (6-b) measurement in horizontal direction at $1 \mathrm{x}$ the frequency equal $2925(\mathrm{CPM})=[48.7 \mathrm{~Hz}]$ the amplitude value is $0.5 \mathrm{~mm} / \mathrm{s}$, at $2 \mathrm{x}$ the frequency equal $5734(\mathrm{CPM})=[95.5 \mathrm{~Hz}]$ the amplitude value is $1.5 \mathrm{~mm} / \mathrm{s}$, at $3 \mathrm{x}$ the frequency equal 8606 $(\mathrm{CPM})=[143.4 \mathrm{~Hz}]$ the amplitude value is $3 \mathrm{~mm} / \mathrm{s}$. Table IIshown as value of amplitude and frequency.

3. In Fig. (6-c) measurement in vertical direction at $1 \mathrm{x}$ the frequency $2934(\mathrm{CPM})=\left[48.9 \mathrm{H}_{\mathrm{Z}}\right]$ amplitude value is $1 \mathrm{~mm} / \mathrm{s}$, at $2 \mathrm{x}$ frequency $5734(\mathrm{CPM})=\left[95.5 \mathrm{H}_{\mathrm{z}}\right]$ the amplitude value is $7.25 \mathrm{~mm} / \mathrm{s}$ and we notice also at 3x frequency 8606 $(\mathrm{CPM})=\left[143.4 \mathrm{H}_{\mathrm{z}}\right]$ the amplitude value is
$2.75 \mathrm{~mm} / \mathrm{s}$. Table III shown as value of amplitude and frequency.

4. It means that there is misalignment fault according to trouble shoot chart at $1 \mathrm{RPM}=2850 / 60=47.5 \mathrm{H}_{\mathrm{Z}}$, misalignment at $2 \mathrm{RPM}=2 * 2850 / 60=95 \mathrm{H}_{\mathrm{z}}$ and $3 \mathrm{RPM}=3 * 2850 / 60=142.5 \mathrm{~Hz}$ [22].In time domain in Fig. 7 shows the relation between time (s) and amplitude $\mathrm{mm} / \mathrm{s}$ in axial, horizontal, and vertical direction, it indicate that misalignment is the cause of vibration.

Table- I: The amplitude value in axial direction.

\begin{tabular}{|c|c|c|c|c|c|c|}
\hline \multirow[b]{2}{*}{ Direction } & \multicolumn{2}{|c|}{$1 \mathrm{x}$} & \multicolumn{2}{|c|}{$2 \mathrm{x}$} & \multicolumn{2}{|c|}{$3 x$} \\
\hline & $\begin{array}{l}\text { Am } \\
\text { plit } \\
\text { ude }\end{array}$ & $\begin{array}{c}\text { Freq } \\
\text { uenc } \\
\mathrm{y}\end{array}$ & $\begin{array}{c}\text { Amp } \\
\text { litud } \\
\mathrm{e}\end{array}$ & $\begin{array}{c}\text { Freq } \\
\text { uenc } \\
\mathrm{y}\end{array}$ & $\begin{array}{l}\text { Am } \\
\text { plit } \\
\text { ude }\end{array}$ & $\begin{array}{c}\text { Freq } \\
\text { uenc } \\
\mathrm{y}\end{array}$ \\
\hline Axial & $\begin{array}{c}14 \\
\mathrm{~mm} \\
/ \mathrm{s}\end{array}$ & $\begin{array}{c}48.4 \\
\mathrm{~Hz}\end{array}$ & $\begin{array}{c}2.75 \\
\mathrm{~mm} / \\
\mathrm{s}\end{array}$ & $\begin{array}{c}95.5 \\
\mathrm{~Hz}\end{array}$ & $\begin{array}{c}4.5 \\
\mathrm{~mm} \\
/ \mathrm{s}\end{array}$ & $\begin{array}{l}143 . \\
4 \mathrm{~Hz}\end{array}$ \\
\hline
\end{tabular}

Table-II: The amplitude value in horizontal direction.

\begin{tabular}{|c|c|c|c|c|c|c|}
\hline \multirow{2}{*}{ Direction } & \multicolumn{2}{|c|}{$1 \mathrm{x}$} & \multicolumn{2}{c|}{$2 \mathrm{x}$} & \multicolumn{2}{c|}{$3 \mathrm{x}$} \\
\cline { 2 - 7 } & Am & Freq & Amp & Freq & Am & Freq \\
plit & uenc & litud & uenc & plit & uenc \\
ude & $\mathrm{y}$ \\
\hline Horizontal & 0.5 & 48.7 & $1.5 \mathrm{~m}$ & 95.5 & $3 \mathrm{~m}$ & 143. \\
& $\mathrm{~mm}$ & $\mathrm{~Hz}$ & $\mathrm{~m} / \mathrm{s}$ & $\mathrm{Hz}$ & $\mathrm{m} / \mathrm{s}$ & $4 \mathrm{H}_{\mathrm{z}}$ \\
& $/ \mathrm{s}$ & & & & & \\
\hline
\end{tabular}

Table- III: The amplitude value in vertical direction.

\begin{tabular}{|c|c|c|c|c|c|c|}
\hline \multirow{3}{*}{ Direction } & \multicolumn{2}{|c|}{$1 \mathrm{x}$} & \multicolumn{2}{c|}{$2 \mathrm{x}$} & \multicolumn{2}{c|}{$3 \mathrm{x}$} \\
\cline { 2 - 7 } & $\begin{array}{c}\text { Am } \\
\text { plit } \\
\end{array}$ & $\begin{array}{c}\text { Freq } \\
\text { uenc } \\
\mathrm{yde}\end{array}$ & $\begin{array}{c}\text { Amp } \\
\text { litud } \\
\mathrm{e}\end{array}$ & $\begin{array}{c}\text { Freq } \\
\text { uenc } \\
\mathrm{y}\end{array}$ & $\begin{array}{c}\text { Am } \\
\text { plit } \\
\text { ude }\end{array}$ & $\begin{array}{c}\text { Freq } \\
\text { uenc } \\
\mathrm{y}\end{array}$ \\
\hline \multirow{3}{*}{ Vertical } & $1 \mathrm{~m}$ & 48.9 & $\begin{array}{c}7.25 \\
\mathrm{~mm} / \\
\mathrm{m} / \mathrm{s}\end{array}$ & $\begin{array}{c}95.5 \\
\mathrm{~Hz}\end{array}$ & $\begin{array}{c}2.7 \\
5 \mathrm{~m} \\
\mathrm{~m} / \mathrm{s}\end{array}$ & $\begin{array}{c}143 . \\
4 \mathrm{~Hz}\end{array}$ \\
\hline
\end{tabular}

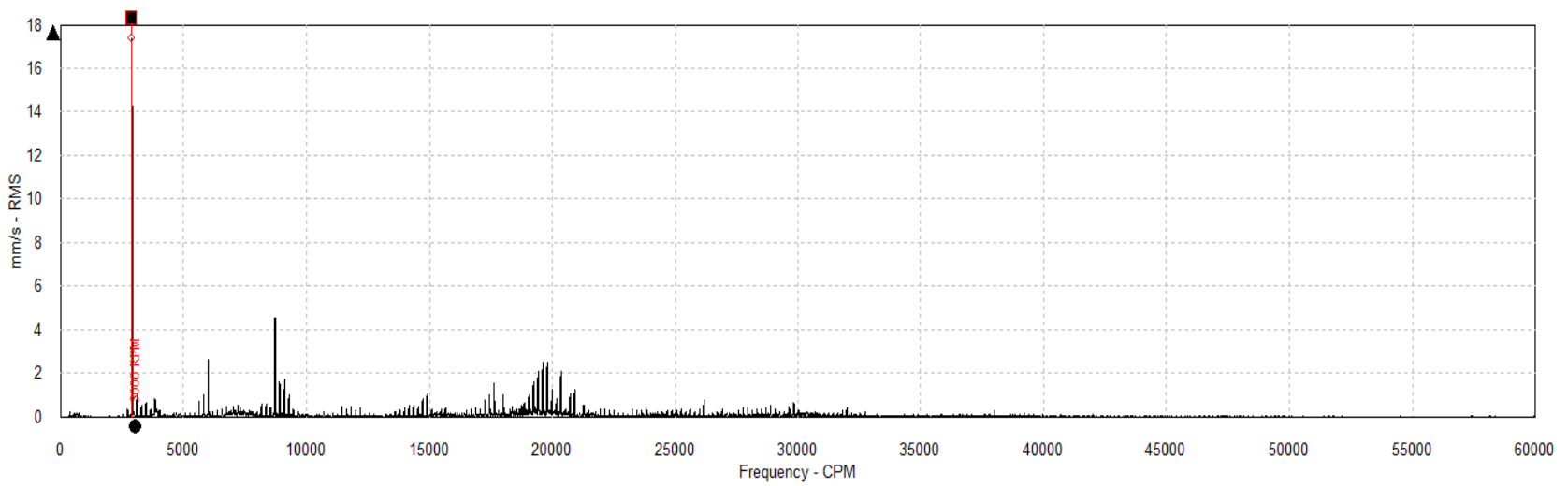

Fig. (6-a). in axial direction

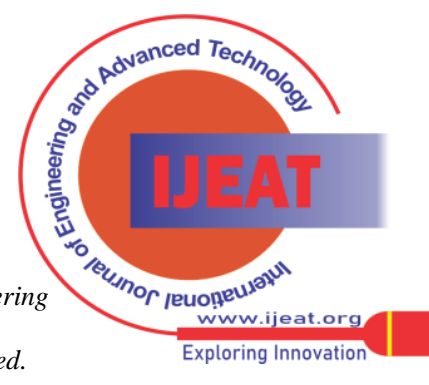




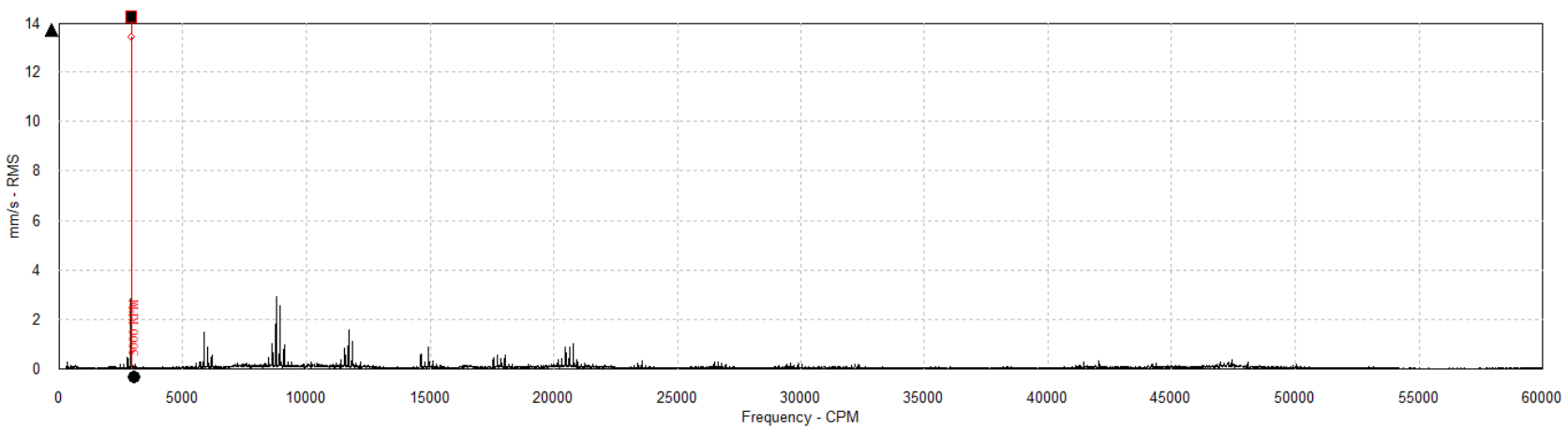

Fig. (6-b). in horizontal direction

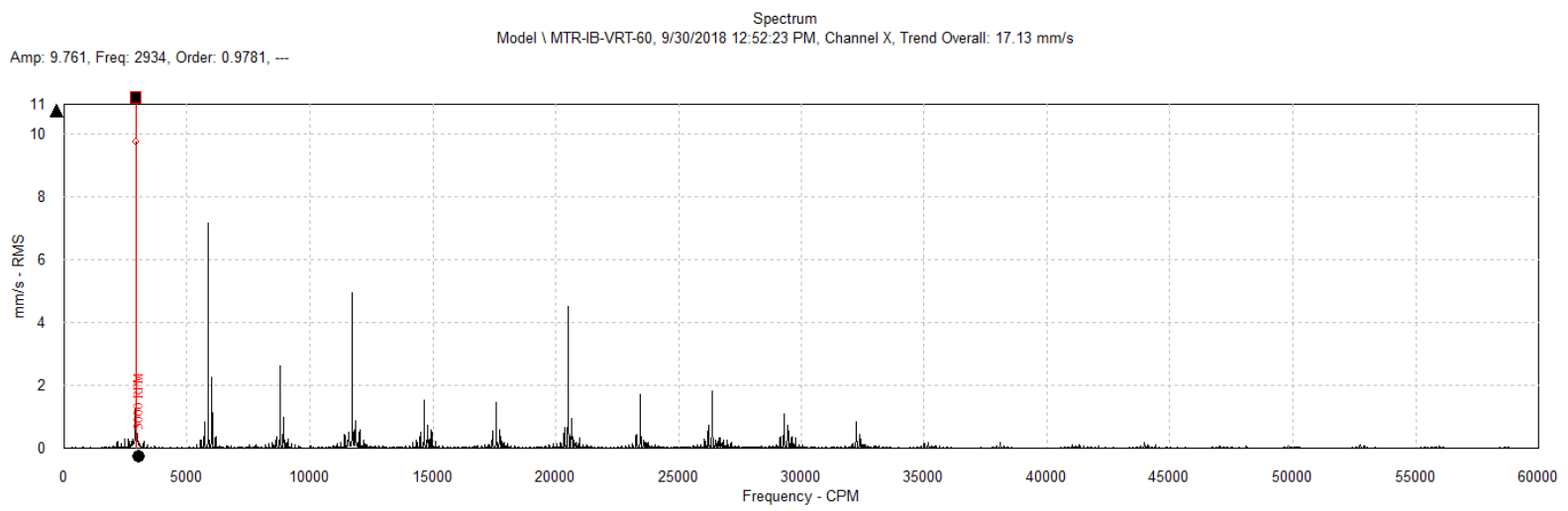

Fig. (6-c). in vertical direction.

Fig.6. Spectrum in frequency domain in axial, horizontal, and vertical directions.

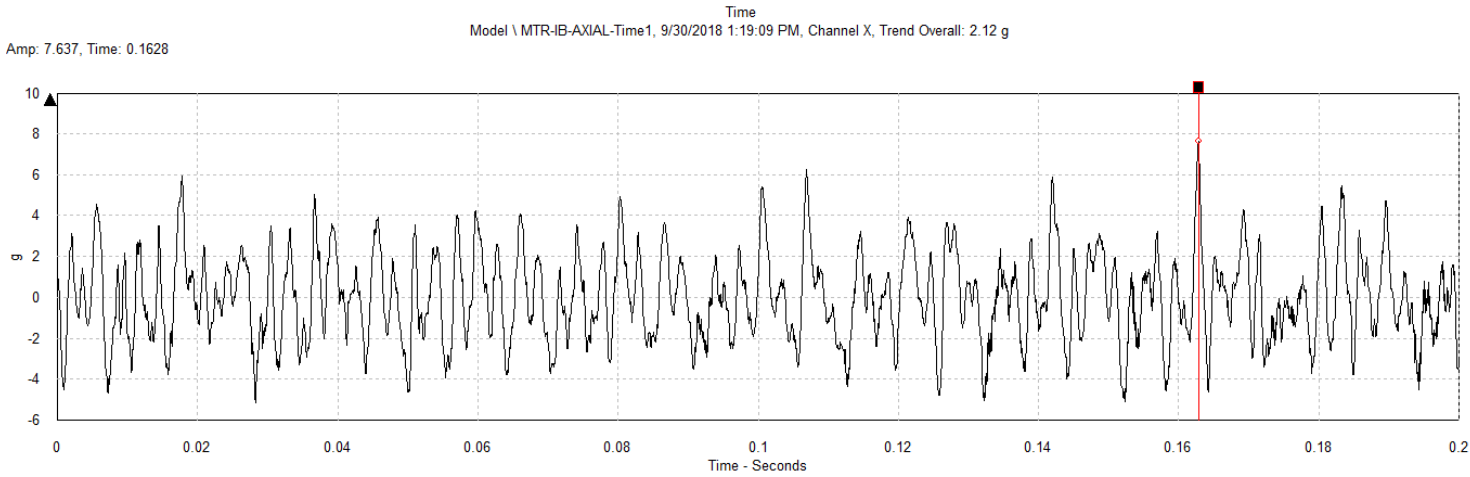

Fig. (7-a). axial direction

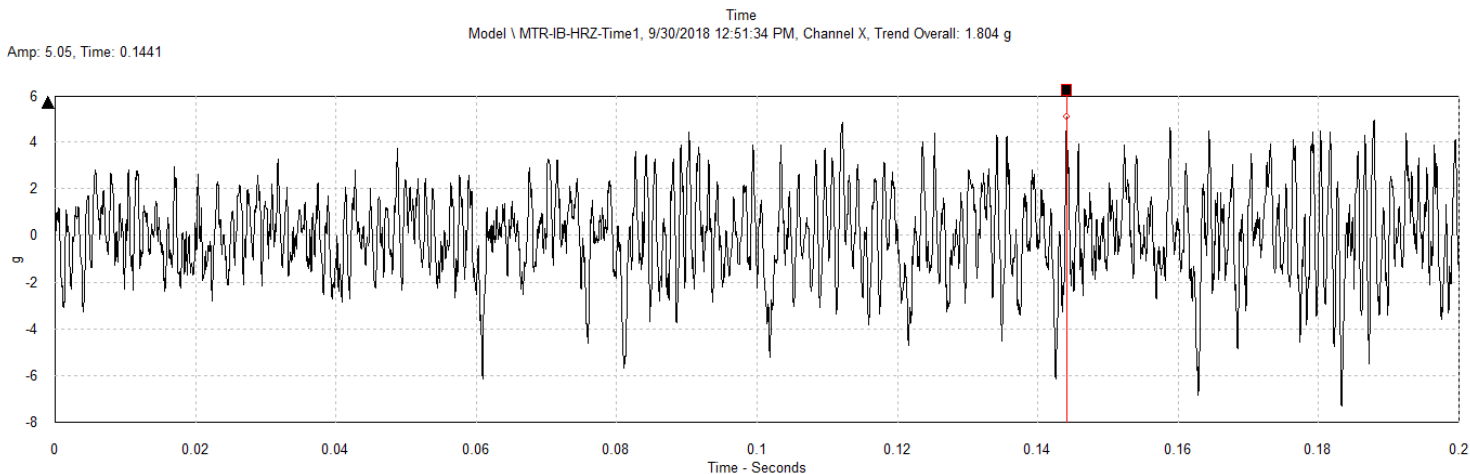

Fig. (7-b). horizontal direction.

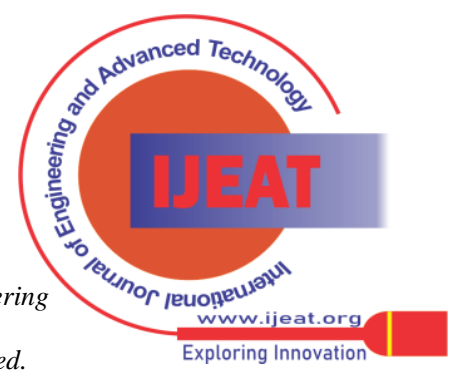




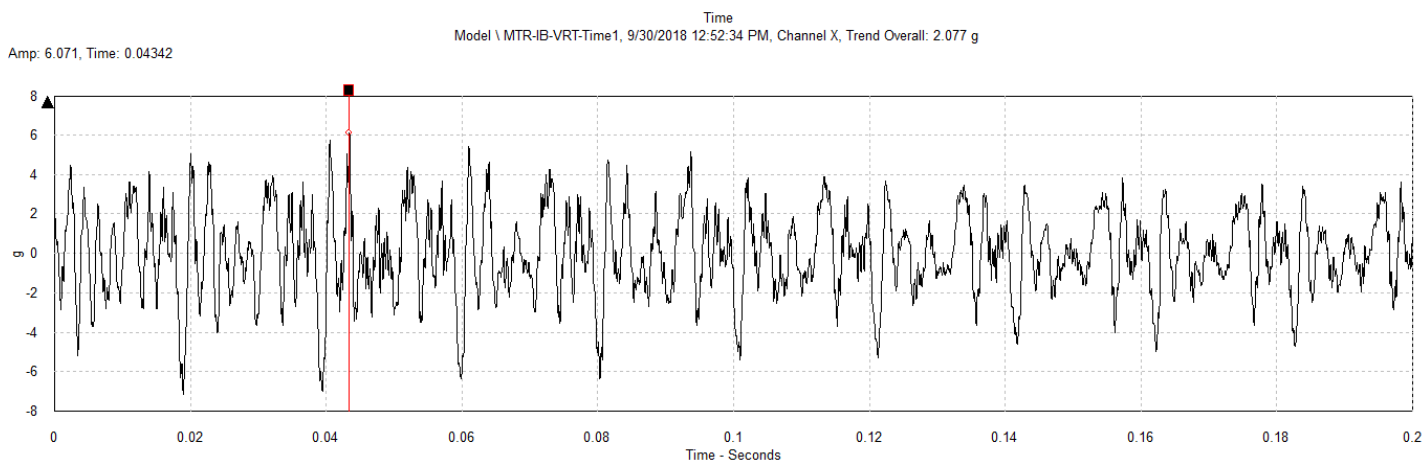

Fig. (7-c). vertical direction.

Fig. 7. Spectrum in Time domain in axial, horizontal, and vertical directions.

Another Sample of spectrum at point (1) at bearing of horizontal, and vertical direction as shown in Fig. 8 and Fig. 9. From Fig. 8 shows the relation between frequency (CPM) and amplitude $\mathrm{mm} / \mathrm{s}$.

1. In Fig. (8-a) measurement in horizontal direction we notice at $1 \mathrm{x}$ frequency $2920(\mathrm{CPM})=\left[48.6 \mathrm{H}_{\mathrm{Z}}\right]$ the amplitude value is $10 \mathrm{~mm} / \mathrm{s}$ and at $2 \mathrm{x}$ frequency $5833(\mathrm{CPM})=\left[97.2 \mathrm{H}_{\mathrm{Z}}\right]$ the amplitude value is $3.5 \mathrm{~mm} / \mathrm{s}$. TableIV shown as value of amplitude and frequency.

2. InFig (8-b) measurement in vertical direction we notice at $1 \mathrm{x}$ frequency $2913(\mathrm{CPM})=\left[48.5 \mathrm{H}_{\mathrm{Z}}\right]$ the amplitude value is $16.5 \mathrm{~mm} / \mathrm{s}$ and at $2 \mathrm{x}$ frequency $5833(\mathrm{CPM})=\left[97.2 \mathrm{H}_{\mathrm{z}}\right]$ the amplitude $3.75 \mathrm{~mm} / \mathrm{s}$. Table $\mathrm{V}$ shown as value of amplitude and frequency.

3. It means the fault is misalignment according to trouble shoot chart which is misalignment appear at $1 \mathrm{RPM}=2850 / 60=47.5 \mathrm{H}_{\mathrm{Z}}$ $2 \mathrm{RPM}=2 * 2850 / 60=95 \mathrm{H}_{\mathrm{Z}}[22]$. and

. In time domain in Fig.9 shows the relation between time (s) and amplitude $\mathrm{mm} / \mathrm{s}$ at point (1) in horizontal, and vertical direction, it indicate that misalignment is the cause of vibration.

Table-IV: The amplitude value in horizontal direction.

\begin{tabular}{|c|c|c|c|c|}
\hline Direction & \multicolumn{2}{|c|}{$1 \mathrm{x}$} & \multicolumn{2}{c|}{$2 \mathrm{x}$} \\
\hline & $\begin{array}{c}\text { Amplitud } \\
\mathrm{e}\end{array}$ & $\begin{array}{c}\text { Frequenc } \\
\mathrm{y}\end{array}$ & $\begin{array}{c}\text { Amplitud } \\
\mathrm{e}\end{array}$ & $\begin{array}{c}\text { Frequenc } \\
\mathrm{y}\end{array}$ \\
\hline $\begin{array}{c}\text { Horizonta } \\
\mathrm{l}\end{array}$ & $10 \mathrm{~mm} / \mathrm{s}$ & $48.6 \mathrm{H}_{\mathrm{z}}$ & $3.5 \mathrm{~mm} / \mathrm{s}$ & $97.2 \mathrm{~Hz}_{\mathrm{z}}$ \\
\hline
\end{tabular}

Table- V: The amplitude value in vertical direction,

\begin{tabular}{|c|c|c|c|c|}
\hline $\begin{array}{c}\text { Directio } \\
\mathrm{n}\end{array}$ & \multicolumn{2}{|c|}{$1 \mathrm{x}$} & \multicolumn{2}{c|}{$2 \mathrm{x}$} \\
\hline & $\begin{array}{c}\text { Amplitud } \\
\mathrm{e}\end{array}$ & $\begin{array}{c}\text { Frequenc } \\
\mathrm{y}\end{array}$ & $\begin{array}{c}\text { Amplitud } \\
\mathrm{e}\end{array}$ & $\begin{array}{c}\text { Frequenc } \\
\mathrm{y}\end{array}$ \\
& & & \\
\hline Vertical & $16.5 \mathrm{~mm} / \mathrm{s}$ & $48.5 \mathrm{H}_{\mathrm{z}}$ & $3.75 \mathrm{~mm} / \mathrm{s}$ & $97.2 \mathrm{H}_{\mathrm{Z}}$ \\
\hline
\end{tabular}

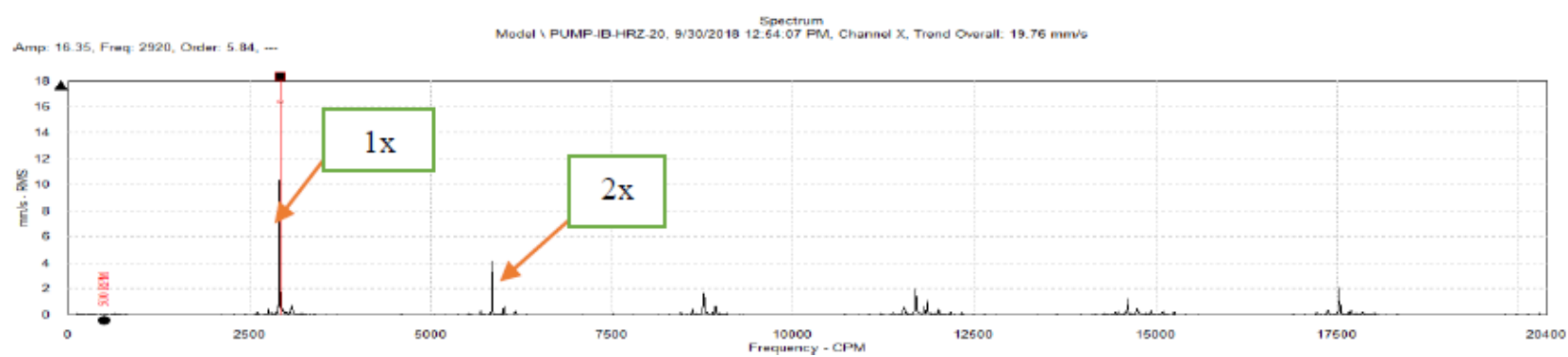

Fig. (8-a) in horizontal direction

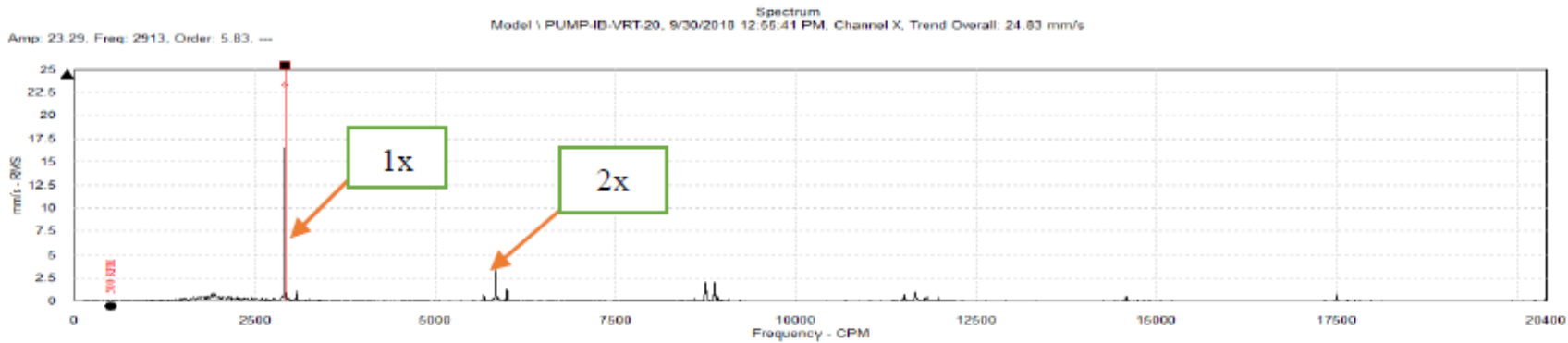

Fig. (8-b) in vertical direction

Fig. 8 Spectrum in frequency domain in horizontal and vertical direction

Published By:

Blue Eyes Intelligence Engineering and Sciences Publication

(C) Copyright: All rights reserved.

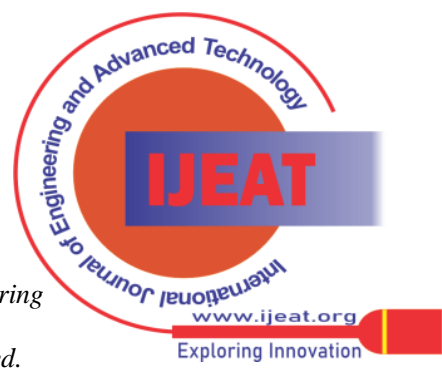




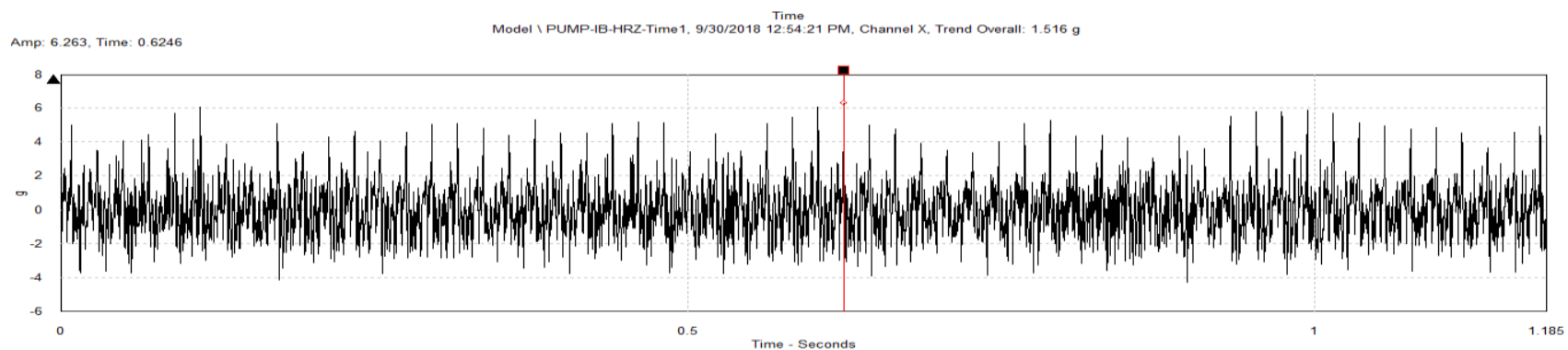

Fig. (9-a) in horizontal direction.

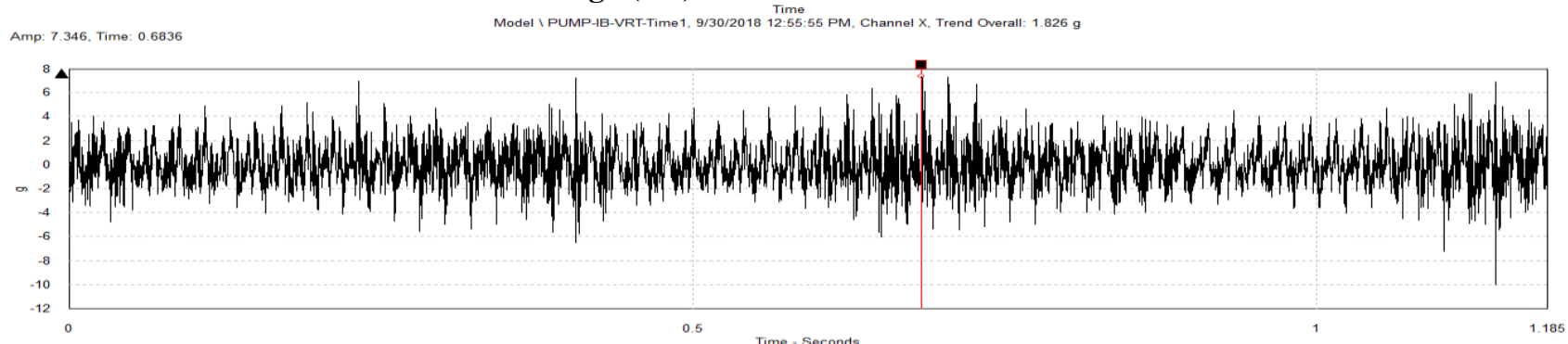

Fig. (9-b) in vertical direction

Fig. 9 Time domain in horizontal and vertical direction.

\section{2-Misalignment measuring}

C. Experiment procedure

To measure misalignment using device TKSA 60 as shown in Fig. 10 and. 11.

- Mount the two V- brackets on the two shaft of motor and rotor by chains, then screw the two rods of each bracket that hold the measuring unit (sensor).

- Make the two sensors aligned manually as much as you can the switch them on.

- After switching it on select to use either horizontal or vertical alignment from the display unit. After connection is done between display unit and two sensors, specify the accurate dimensions of the system by using meter. Specify the convenient alignment tolerance based on RPM according to ISO standard.

- The horizontal alignment machine dimensions:

- The distance between two measuring units, from the centers of the rods equal $7 \mathrm{~cm}$.

- The distance between the measuring unit and the front foot of the movable machine(motor) (center of foot) equal $1.5 \mathrm{~cm}$. note that this may be negative, if necessary.

- The distance between the front and back feet of the movable machine (motor) (center of feet) equal $8.5 \mathrm{~cm}$.

- The distance between two bearings equal 36.5 $\mathrm{cm}$.

- The distance between the bearing near of coupling and the measuring unit equal $9 \mathrm{~cm}$.

- The Tolerance equal to $0.07 \mathrm{~mm}$.

- $\quad$ Take 3 measurement at 3 different positions e.g at 12, 3 , and 9 o'clock as an initial inspection.

- Misalignment results(values) will be displayed in the horizontal and vertical directions.

- While the sensors are at 12 o'clock, correct misalignment first in the vertical direction by adding or removing shims from the movable motor unit reach the required value
- While the sensors are at 3 or 9 o'clock, correct misalignment in the horizontal direction by moving the motor either toward or away from the user's view point until reach the required value.

- Fig.12 and table.VI shows the measurement result.

- From Fig.12 and Table. VI Angular misalignment the measurement result is more than twice the specified tolerance. Parallel misalignment the measurement result is between $1 \mathrm{x}$ and $2 \mathrm{x}$ the specified tolerance.

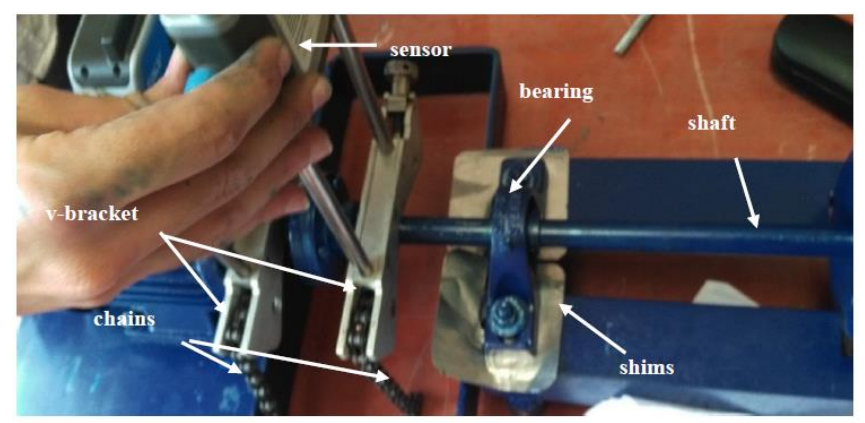

Fig. 10 Measuring misalignment in vertical direction.

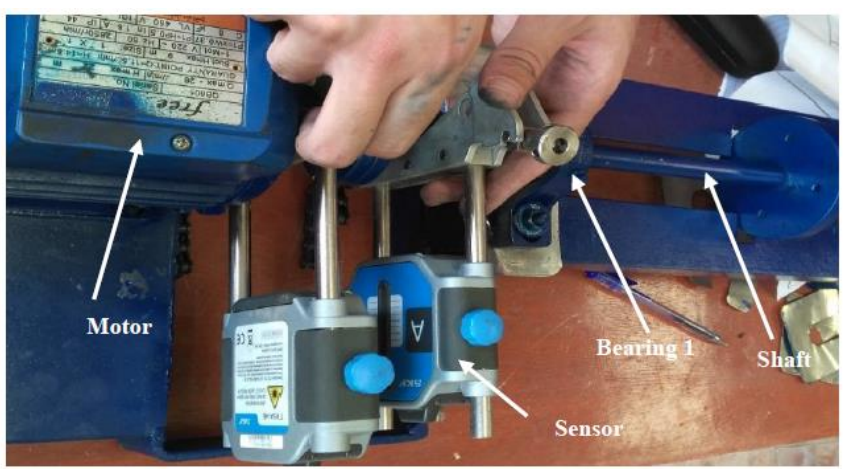

Fig. 11Measuring misalignment in horizontal direction.

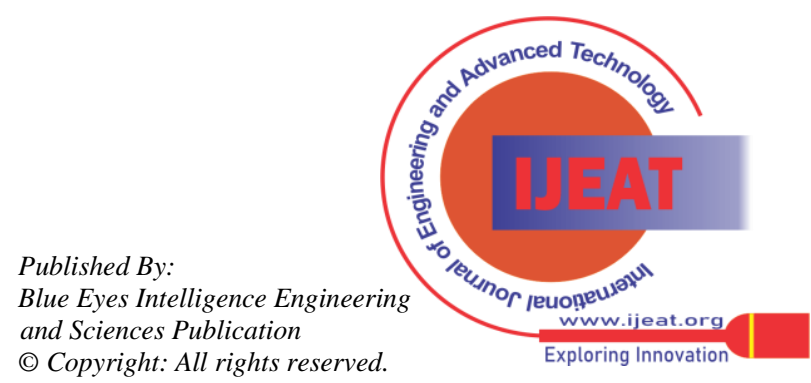




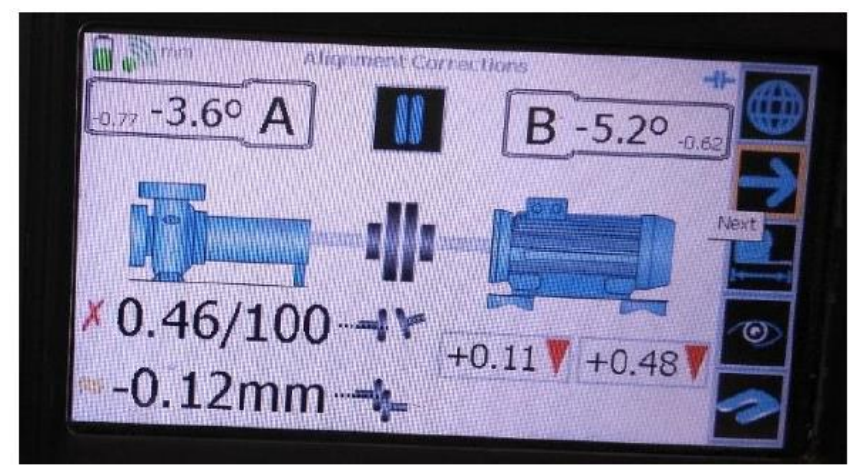

Fig. 12 Measurement result.

Table- VI: Result misalignment.

\begin{tabular}{|c|c|}
\hline Angular misalignment & Parallel misalignment \\
\hline $0.46 / 100$ & $-012 \mathrm{~mm}$ \\
\hline
\end{tabular}

\section{CONCLUSION}

Vibration measurement and analysis is one of the most important method used for machine conditionmonitoring to detect and diagnose faults in the rotating machinery. This could help us to avoid sudden stoppage, save cost and time. Misalignment is one of the most common faults in the rotating machinery, it is most important fault because it affects the other components condition if not corrected early.

The presented study focuses on misalignment through vibration measurement and analysis in both frequency and time domains. The result from Fig. 6 and 7 show increases in peaks in frequency domain, time domain at 1,2,3 $\mathrm{X}$ in axial direction and vertical direction which are referred to misalignment fault. Using Laser alignment device to quantify increase misalignment in both angular or/and parallel then using shims as required to create artificial misalignment. The presented study focuses on misalignment fault detection using spectrum analysistechnique. The results are monitored using vibration device.

\section{REFERENCES}

1. N. Tenali, Dr P. Babu, and K. Ch. Kuma "Vibrational analysis in condition monitoring and faults diagnosis of rotating shaftoverview", International Journal of Advanced Engineering Research and Science (IJAERS), Vol. 4, Issue-1, Jan 2017.

2. P. Jayasway, A. K. Wadhwani, and K. B. Mulchandani, "Review Article machine fault signature analysis", International Journal of Rotating Machinery, Article ID583982, 10 pages, doi: 10.1155/2008/583982, 2008.

3. B. El A nouar, M. Elamran, B. Elkihel, and F. Delaunois, " A comparative experimental study of ultrasound technique and vibration analysis in detection of bearing defect", presented at 13 emeCongres de Mecanique, (Meknes, MAROC), https://cmm2017.science sconf.org/129197/document, pp.11-14, April 2017.

4. R. Yany, J. Kang, J. Zhao, J. Li, and H. Li, "A case study of bearing condition monitoring using SPM", in Prognostics and System Health Management Conference (PHM-2014Hunon), pp. 695-698, 2014.

5. D. Goyal et.al, "Condition monitoring of rotating machines: A review", An International Scientific Journal, WSN 113(2018)98-108, 2018.

6. F. Wang et.al, "Condition monitoring and fault diagnosis methods for low-speed and heavy-load slewing bearings: A literature Review", DOI https://doi.org/10.21595/jve.2017.18454,2017.

7. M. A. Eissa, F. R. Gomaa, and K. M. Khader, "Bearing 'searlyfaultdetectionusing vibrationanalysis", 18 th International Conference on Applied Mechanics and Mechanical Engineering, 3-5 April, 2018.

8. Dubravko et.al, "Brief Review of Vibration Based Machine Condition Monitoring”, dubravko.miljkovic@hep.hr

9. B. Tchomeni, A. Alugono, and L. Masu,"A fault analysis crackedrotor-to-stator rub and unbalance by vibration analysis technique", International Journal of Mechanical, Aerospace, Industrial, Mechatronic and Manufacturing Engineering, Vol.9, pp. 1883-1892, 2015.

10. S. S. Rudraraju, "Vibration analysis basedmachine unbalance faultdetection and correction", Indian Schoolof Mines Dhanbad, India January-May 2005.

11. A.Q u et.al, "Gearbox tooth cut fault diagnositics using acoustic emission and vibration sensors- a comparative study", Sensors, Vol.14, pp. 1372-1393, 2014.

12. S. Patidar, and P. K. Soni, "An Overview on vibration analysis techniques for the diagnosis of rolling element bearing faults", International Journal of Engineering Trends and Technology(IJETT)-Vol.4 Issue5-May2013.

13. Vishnukv, A. BK, and Adarshks, "Vibration analysis: a literature review", IOSR Journal of Electronics and Commumication on Engineering (IOSR-JECE), e-ISSN:2278-2834, p-ISSN:2278-8735 Vol.10, Issue 5, pp. 35-39, Ver. I (Sep-Oct.2015), www.iosrjournals.org

14. Eng. Akra<www. Drahmednagib.com, "Practical_Machinery Vibration_Analysis_and_Predictive.Maintenance" pdf.

15. A. K. Verma, S. Sarangi, and M. H. Kolekar, "Shaft misalignment detection using stator current monitoring", International Journal of Advanced Computer Research(ISSN(print) 2249-7277 ISSN(online):2277-7970) Vol.3Number-1ISSue-8 March. 2013.

16. J.Nalawade, Pr. K. B. Kolekar,"An Experimental investigation of effects of misalignment of shaft of AC motor using vibration analysis", International Journal of Advance Engineering and Research Development, Vol.4, Issue 4, April. 2017.

17. A. F. Ab Ghani, M. A. A. Razali, Z. Zainal, and F. Idral, "Detection of shaft misalignment using machinery fault simulator(MFS)", Journal of Advanced Research in Applied Sciences and Engineering Technology ISSN(online):2462-1943| Vol. 4, No.1. P. 47-54, 2016

18. A.Simm, Q. Wang, S. Huang, and W. Zhoa, "Laser based measurement for the monitoring of shaft misalignment", Journal homepase:www.elsevier.com/Locate/measurement.

19. S.P.Naik, Prof. D. P. Hujare, and Dr. M. G. Karnik, "Experimental study of parallel misalignment in shaft rotor system using vibration signature analysis", International Engineering Research Journal page NOC 1431-1434, 2016.

20. C. Verucchi, and J. Bossio, "Misalignment detection in induction motors with flexible coupling by means of estimated torque analysis\& MCSA", Mechanical System\& Signal Processing, 2016.

21. M.Nataraj, and G. Baskaran, "Experimental investigation of misalignment and looseness in rotor bearing system using Bartlett power spectral density". Journal of Scientific \& Industrial Research Vol.76, pp.308-313,May 2017.

22. John S. Mitchell, "Machinery Analysis and Monitoring”, Penn Well 1981.

\section{AUTHORS PROFILE}

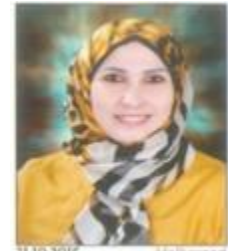

D. H. Omar, I completed undergraduate, in Production Engineering and Mechincal design, Faculty of Engineering, Menoufia University, Shebin-ElKom, Egypt. Currently Master student in the same University.

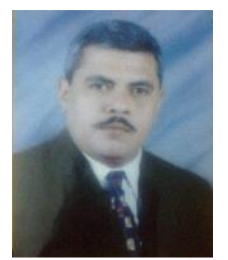

Mohamed Hesham Ahmed Belal, was born on November 2, 1959 in Shebin-Elkom, Menoufia region, of Egypt. In 1982 he graduated from Production Engineering \& Mechanical Design Department Faculty of engineering. He began his career at Faculty of Engineering, Production Engineering \& Mechanical Design Department, Menoufia University, from 1984. M.Sc. title was Vibration Analysis of structural foundation of machines combining types of connections considerations.

Published By:

Blue Eyes Intelligence Engineering and Sciences Publication

(C) Copyright: All rights reserved.

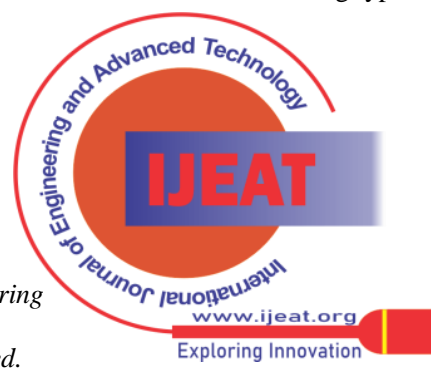


Ph.D. title was Dynamics of Viscoelastic Mechanical Systems. He interested if the fields of Dynamics of machines and maintenance E-mail heshambelal@gmail.com - phone +201005616160

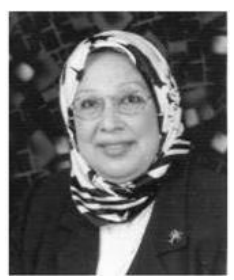

F. R. Gomaa, Professor of machine dynamic\& structures., Faculty of Eng., Minoufiya University

- $\quad$ Teaching and Research Topics

Machinery Dynamic, Vibration \&Diagnosis

- $\quad$ Teaching Undergraduate and Graduate courses [Machine dynamics ( Structural dynamics, Advanced Industrial Maintenance), Design of Machine Elements, Design of Hydraulic and Pneumatic equipment's, Advanced Measurements ,Metrology and B.Sc. projects.

- $\quad$ Supervisor master , doctor in field of dynamics - diagnosis\& robot. - $\quad$ Found member in Arabian Society of Diagnostic Engineers

Experimental Investigation For Dynamic Characteristics On Pneumatic Modal Of Loader Mechanism.

"Experimental Investigation for Dynamic Behavior of WeldedCrackedBeam". Vibration Control Using Complex Modal Damping "Thermal Cycling of Aluminum Composites.

"Modeling of VibrationDamping in Composite Structures.

"An ImprovedDynamic Modeling of Fiber Reinforced Laminated Composite Structures.

"Avoidance of Harmful Effects of Vibration and Noise On Human Body

"Generalized Model of Vibratory Damped Glass Reinforced Plastic

(GRP)".

"Vibration Analysis of a Non-Linear Vibratory Conveyor".

"Inherent Damping Criteria of CarbonFiber Reinforced Plastic".

"Fatigue life Estimation of 6061 Aluminum alloy based onModal Damping measurements Engineer".

"Prediction of Fracture of Eggs shell Using Operational Modal Analysis

" Fault Monitoring in Complex Dynamic System Utilizing Statistical Analysis Technique.

"Operational Modal Analysis and Damage Dection in Fruit Quality Assessment Using Different Methods of Packaging.

"Damage Detection in Structures Using Operation Deflection Shape",

"Application of condition monitoring using operation deflection to Detect damage in rotating machinery “

"Health Monitoring of Packed Agricultural Products Using Dynamic Analysis.

"Validation Study Illustrates the Accuracy of Operational Modal Analysis Identification".

"Output-Only Modal Identification And Monitoring Transmitting Products In the Presence Of Harmonic Force"

"Dynamic Analysis of Tool Holder with Damping Estimation".

"Sensitivity of Modal Parameters to detect Damage through Theoretical and Experimental Correlation"

computer Aided Design of Multi-Stage Gearboxes

Structural Modifications of 1K62Engine Lathe Gear box 'Casing

"Fault Diagnosis of Rotating Machinery based on vibration analysis.

Estimation of Milling Stability Lobes Through Operational Modal Analysis for Composite Materials

Stability Lobe Diagram of End Milling for Composites Using Semi Discretization Method .

Machine health monitoring using vibration analysis.

Bearing's early fault detection using vibration analysis.

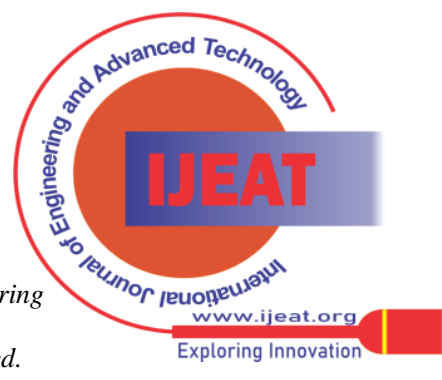

